\title{
Uma economia política da poesia drummondiana
}

[ A political economy of Drummond's poetry

\section{Alexandre de Freitas Barbosa ${ }^{\mathrm{I}}$}

WISNIK, José Miguel. Maquinação do mundo: Drummond e a mineração. São Paulo: Companhia das Letras, 2018.

RESUMO - O texto procura ressaltar a contribuição de José Miguel Wisnik em seu livro recente. Nessa obra, o autor realiza uma fusão entre a história do desenvolvimento e da mineração no Brasil, que teve como marco a criação da Companhia Vale do Rio Doce (CVRD), e a invenção poética drummondiana, profundamente afetada pelo destino de Itabira, sua cidade natal. Tempo e espaço são aniquilados durante o processo de desenvolvimento econômico, mas também ressignificados criativamente pelo poeta, que vê o território onde se deu o seu processo de sociabilidade ser literalmente soterrado pela atuação da empresa. A Vale S.A., tal como renomeada em 2007, apenas depois das catástrofes de Mariana e Sobradinho parece ecoar o grito de dor do poeta, cuja inteligibilidade não era acessível aos seus contemporâneos.. PALAVRAS-CHAVE
- Poesia; Drummond; mineração; ferro; desenvolvimento. • ABSTRACT - The paper seeks toshed light on José Miguel Wisnik's contribution in his recent book. He integrates the history of development and mining in Brazil, which had as one of its hallmarks the creation of Rio Doce Valley Corporation (CVRD in Portuguese), and Drummond's poetic invention, deeply affected by the fate of Itabira, his hometown. Time and space are totally shattered by the process of economic development, but also creatively resignified by the poet who sees the territory of his early sociability buried by the enterprise activity. Vale S.A., as it was renamed in 2007, only after the tragedies of Mariana and Brumadinho seems to convey the poet's echo of pain, not intelligible by his contemporaries. - KEYWORDS - Poetry; Drummond; mining; iron; development.

Recebido em 20 de maio de 2019

Aprovado em I3 de junho de 2019

BARBOSA, Alexandre de Freitas. Uma economia política da poesia drummondiana. Revista do Instituto de Estudos Brasileiros, Brasil, n. 73, p. 275-279, ago. 2019.

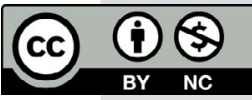

DOI: http://dx.doi.org/Io.II6o6/issn.23I6-90IX.voi73p275-279

I Universidade de São Paulo (USP, São Paulo, SP, Brasil). 
Em Maquinação do mundo: Drummond e a mineração, José Miguel Wisnik conseguiu a proeza de incluir o poeta Carlos Drummond de Andrade, junto com Caio Prado Jr. e Celso Furtado, na bibliografia obrigatória dos cursos de Formação Econômica do Brasil das nossas universidades.

A obra empreende uma fusão entre a industrialização, o projeto de desenvolvimento e as negociações internacionais do país, por um lado, e a obra poética de Drummond, marcada por seu "destino mineral" itabirano, por outro. Essas duas faces do real aparecem enredadas na mesma trama. Uma não se reconhece (nem sequer parece existir) sem a outra, tal o êxito logrado na colagem desses dois mundos.

O objetivo de Wisnik não é traçar de maneira cronológica as pegadas de Itabira na obra do autor. É a própria obra literária de Drummond que aparece ressignificada à medida que o autor historiciza a geoeconomia que lhe serve de matéria-prima. Esse pano de fundo permite uma nova forma de acesso à obra literária. Em vez de forçar a barra, empurrando a análise "econômica" para dentro da obra drummondiana, em Wisnik é sempre a "poesia que decide".

Itabira, território que se verga à extração de minério, com base nos Acordos de Washington (I942) negociados por Osvaldo Aranha - então embaixador de Vargas nos Estados Unidos - , deveria permitir o ingresso do Brasil no mundo moderno por meio da siderurgia. Isso de fato aconteceu. $\mathrm{O}$ outro lado da história foram as pedras deixadas no caminho.

Hoje sabemos que as barragens feitas de rejeitos engoliram o rio que dava nome à Vale - sem o Rio Doce no título desde 2007 - , destruíram a natureza e mataram centenas de trabalhadores e moradores de Mariana e Brumadinho. A obra-prima de Wisnik, marcada por essa catástrofe contemporânea, nos revela (teria sido possível fazê-lo antes?) que a catástrofe de Itabira não era mero instrumento retórico do poeta de origem provinciana. Ali ele se fez cosmopolita e teve acesso ao sentimento do mundo. O seu peito fora marcado a ferro. Drummond, ao acionar a sua "máquina poética", fez dessa substância tóxica - "veneno remédio" - a matéria-prima que lhe permitiu levar a poesia do século XX ao seu pico mais elevado.Creio ser essa a mensagem principal do autor da obra.

2 Trata-se de uma alusão ao título do livro anterior do autor, publicado pela Companhia das Letras em 2008. 
Vejamos por quê. Itabira conforma o espaço real e simbólico em que o poeta se move na sua infância e adolescência. Se o sino da igreja é o marcador do tempo que acompanha o poeta funcionário na capital federal, o pico do Cauê preenche a vista que ele tinha do sobrado patriarcal, estrategicamente posicionado de modo a imprimir o seu lugar privilegiado naquela sociedade.

A história de Itabira significa a eliminação literal do tempo e do espaço, que compõem o chão (pedra) e o céu (mundo) emotivo do poeta, por meio da fúria avassaladora do processo de industrialização, simbolizada pela Companhia Vale do Rio Doce (CVRD). Trata-se de um "acaso objetivo", termo emprestado pelo autor dos surrealistas (p. IIo) , sem o qual não se compreendem as transmutações processadas na sua obra desde Alguma poesia (I930), passando por Sentimento do mundo (I940) e Claro enigma (I95I), até chegar a Boitempo (I973). Tal como o acaso que levou Wisnik a Itabira em 20I4, para uma feira literária, um ano antes da tragédia de Mariana, quando então pôde ver o mundo de Drummond, ou o que restara dele.

Logo ao início do livro, Wisnik se refere a Itabira como "um mundo em que o mundo vai engolindo o mundo" (p. 29). Como não pensar em Fernand Braudel e a sua "economia-mundo" tentacular? - que não abarca todo o mundo, pois é "um mundo em si mesmo", estabelecendo conexões a partir da camada superior em que se situa o lugar do capitalismo, conforme a sua definição (BRAUDEL, I996, p. 9-IO, I2-I4, 35). Um mundo polarizado e escalonado em que a sede por extração de excedente "come espaço", incorporando regiões que até então eram "zonas de silêncio". Wisnik é braudeliano sem o saber quando narra "o assalto da história mundial" a essa "cidadezinha qualquer" (p. 39). Afinal, não diz o poeta no poema "América" do livro A rosa do povo: "uma rua começa em Itabira que vai dar em qualquer parte da terra"? Seria Drummond também braudeliano?

Até a estrutura triádica Wisnik empresta inconscientemente do historiador francês, pois o pico do Cauê é a um só tempo a "matéria primal" da história da localidade - "cada um de nós tem o seu pedaço no pico do Cauê", verso de Alguma poesia (p. 45) - , a "matéria-prima" da indústria pesada em alta escala, e a "matéria primeira” da imaginação poética (p. 4I-43). Reunidas em uma trama complexa, essas dimensões se entrosam e se atritam, gerando faíscas e explosões reais e criativas, enquanto o tempo corre "celerado" na sua ânsia de transformar em mercadoria a cidadezinha qualquer.

A cada lance da trama - iniciada, em I9II, com a concessão das jazidas itabiranas ao capital internacional, sob o comando do tubarão Percival Farquhar, passando por I939, quando a concessão é cassada em pleno Estado Novo, e depois quando as jazidas são convertidas em fonte de minério exportado para os Estados Unidos e a Inglaterra - , "o passado volta insistente como matéria do presente” (p. 44). Até se tornar, no ato final, "presença alucinada da ausência" (p. 35).

O mesmo poeta que ensaiara uma adesão ao projeto de desenvolvimento nacional, ao fornecer como "prenda" de Itabira, dentre outras, "essa pedra de ferro, futuro aço do Brasil” (em "Confidência do Itabirano", Sentimento do mundo, p. 94), agora bate em retirada. Drummond elimina o verso-prenda das edições seguintes a I940 (p. I03-I04), frustrado com o destino de Itabira, moeda de troca na geopolítica internacional, e mais ainda - pode-se cogitar -, com a sua própria recaída nacionalista. Faria alguma 
diferença se o ferro de Itabira tivesse se transformado em aço nacional, e não em divisas a preço de banana? Ou quem sabe a crítica drummondiana à economia política do desenvolvimento contenha outras dimensões a serem escavadas por futuros pesquisadores?

A história recontada por Wisnik se "vale" dos poemas, das crônicas e dos artigos de jornal em que o grito do poeta ambientalista avant la lettre ecoa no silêncio coletivo. Em sua densa pesquisa, o autor "escava" os destroços do projeto industrializante, então abraçado por tantos corações e mentes, tal como impressos na poesia drummondiana e na sua Itabira. A transmutação definitiva do poeta se dá com Claro enigma, que marca "o fim da longa fase de latência do destino mineral, dando início a um estado de inconformidade impotente” (p. I45).

No início do segundo Vargas, quando o projeto de desenvolvimento ganha fôlego, ele encontra em Drummond um dos seus mais veementes críticos. Pois lhe é facultado penetrar no âmago do processo. Em I948, ao se deparar enlutado, na última visita à sua mãe enferma, com o morro destroçado, num táxi-aéreo fornecido pela CVRD, parece-lhe claro o enigma: ele vira e sofrera na pele o "ponto escuro e doloroso" (p. 70) do desenvolvimento capitalista ainda no seu germe.

A destruição do pico do Cauê ("montanha virada do avesso na forma de um sino descomunal", segundo Wisnik), a conversão da antiga fazenda de sua família em um depósito de rejeitos, o desabamento da Igreja da Matriz do Rosário junto com o "sino Elias" e a transformação de Itabira em canteiro de obras (p. 36-37, I33) desnudam o fetiche da mercadoria.

Drummond olha para trás, com suas "retinas fatigadas", e percebe que o anjo da história se faz acompanhar, tal como em Walter Benjamin, na alusão certeira de Wisnik, por um amontoado de ruínas. Enquanto isso, os militares e seus milagres ensaiam o slogan "Pra frente, Brasil" (p. II9), e a empresa exulta embalada pelo coro. O pesquisador, travestido de crítico literário, descobre no meio de tantas pedras uma pérola: o anúncio, matéria paga, da CVRD, publicado, em 20 de novembro de I970, no jornal O Globo, com o seguinte título: "Há uma pedra no desenvolvimento brasileiro" (p. II7). Nosso poeta é a pedra.

Ao fim e ao cabo, Wisnik nos brinda não apenas com uma releitura da história do projeto de desenvolvimento (capitalista) no Brasil a partir da obra de Drummond. Ele abre uma nova chave de leitura à obra do poeta, trazendo para o centro da cena a "presença semioculta da mineração" (p. I88, p. 233), até então tratada como detalhe biográfico por boa parte da crítica literária especializada. Talvez porque, antes de Mariana e Brumadinho, esses conteúdos não fossem acessíveis. Hoje, Itabira é aqui, está em todos os lugares.

Wisnik nos convida, assim, a reler Drummond. Os seus primeiros poemas, quando o "mundo mineral" aparece de forma "tangencial" e "elíptica", ganham renovada profundidade. Como se a economia iluminasse a política. Já nos poemas maduros de Boitempo, tal como ele nos demonstra, desaparecem a rebeldia modernista e a amargura gerada pela posição social. O pai já se encontra "sepultado na memória", e o poeta encara de maneira objetiva e serena o seu lugar no mundo. Aqui a poesia ilumina a economia do Brasil patriarcal convivendo com os arroubos de modernidade. 
A resenha pede um arremate. Com esse livro, José Miguel Wisnik produziu uma obra da mesma envergadura que Roberto Schwarz (2000) em Um mestre na periferia do capitalismo: Machado de Assis, que descortina o Brasil de Machado de Assis. Cada um a sua maneira e com seu método de lapidar. Literatura e sociedade justapostas, contrapostas, em profunda interação. Um corpo (a literatura) atado a outro corpo (a sociedade), do qual faz parte e transcende. Não à toa, discípulos do nosso ourives-mor, o mestre Antonio Candido.

SOBRE O AUTOR

ALEXANDRE DE FREITAS BARBOSA é professor de História Econômica e Economia Brasileira do Instituto de Estudos Brasileiros da Universidade de São Paulo (IEB/USP).

E-mail: afbarbosa@usp.br https://orcid.org/oooo-0002-0493-7488

\section{REFERÊNCIAS}

BRAUDEL, Fernand. O tempo do mundo. v. 3. In: . Civilização material, economia e capitalismo: séculos XV-XVIII. Rio de Janeiro: Martins Fontes, I996.

SCHWARZ, Roberto. Um mestre na periferia do capitalismo: Machado de Assis. São Paulo: Duas Cidades/ Ed. 34, 2000. 